\title{
Influence of Teaching Resources in Chemistry Practicals on Performance in Chemistry Subject
}

\author{
Ronoh Obadiah Cheruiyot ${ }^{1 *}$, Peter Waswa Nyongesa ${ }^{2}$, Lusweti Kituyi ${ }^{3}$ \\ ${ }^{1,2}$ Department of Center for Teacher Education, University of Eldoret, Kenya \\ ${ }^{3}$ Department of Chemistry \& Biochemistry, University of Eldoret, Kenya \\ Corresponding author*
}

\begin{abstract}
Background: Experimental practices in Chemistry are vital as an instructional method for better understanding of concepts. The study was done to determine the influence of teaching resources in chemistry practicals on performance in chemistry subject. The objective of the study was to ascertain definitely how teaching resources in chemistry practicals influenced performance in the entire subject. Methodology: A survey design was adopted where a sample size of three hundred and seventy seven respondents were selected in a random manner from teachers who instructed chemistry and a cohort of students in the third year from secondary schools sponsored by the Kenyan government in Narok County. The instruments for data collection were questionnaire, interview and observation schedule. The data obtained were analyzed statistically using SPSS software and Analysis of Variance (ANOVA). Results: The findings indicated that majority of laboratories were not equipped with apparatus and reagents for conducting practical. Time allocation was somehow sufficient for handling practicals but inadequate for individualized activities. Teaching resources contributed significantly to performance in chemistry subject $(\mathbf{P}<0.05)$. Conclusion/Recommendation: Majority of laboratories were not well equipped with apparatus and reagents. Time was inadequate for individualized practices. The government should provide adequate funding of science laboratories to enhance practical instruction in secondary schools
\end{abstract}

Keywords: Teaching, Resources, Practical, Performance

\section{INTRODUCTION}

$\mathrm{C}$ hemistry includes activities that are hands-on and mainly performed by the students. A research facility may be a school building equipped with offices, materials and device which students' utilize, to carry out investigations (Achimugu, 2012). Agreeing to Odum, (2013), Chemistry viable exercises are usually done in a research facility by utilizing pieces of device and chemical reagents.

Practicals contribute to poor performance in sciences when students lack exposure (KNEC, 2009). From research it was realised that few students truly felt they would have performed way better in case they had been instructed periodically in practicals on time. It is contended that students tend to get it and review what they see more than what they listen to as a result of utilizing research facilities to learn sciences, but most schools need research facilities which are functional (Edomwonyi-Otu, 2011).
Adalikwu and Iorkpilgh (2013) explored the impact of instructional resources on students' scholastic execution and found that students taught using instructional materials performed essentially superior than those instructed without. Instructional materials enhanced students' understanding of concepts leading to high academic performance.

Chen and Wei (2015) explored the factors that influenced teachers' adjustments of the educational program materials of modern senior secondary chemistry in China. It was found that there were seven variables that drove teachers' to adopt the use of educational programs materials, and these components were teacher's pedagogical Content Knowledge (PCK), external examinations, time limitation, teachers, number of students, conviction in science and peer coaching. Among these variables, teacher's PCK, external examinations and time imperative were components that affected teachers' adjustments of educational modules materials.

Kenya National Examinations Council (KNEC) (2013) reported that, while the number of students taking chemistry in secondary schools has been high, their performance in practical examination is wanting. This report suggested that students were unable to skillfully manipulate the apparatus, make accurate observations and also fail to make accurate records to be used in making scientific conclusions.

Generally, performance in chemistry as a science subject has been below average over the years as revealed by the KNEC results that in the year 2009, a total of three hundred and twenty-nine thousand, seven hundred and thirty $(329,730)$ candidates sat for KCSE chemistry examinations and obtained a mean score of 38.28 equivalent to $21.14 \%$. Three hundred and forty-seven thousand, three hundred and sixty-four $(347,364)$ candidates sat for KCSE chemistry examinations in the year 2010 and obtained a mean score of 49.84 equivalent to $27.98 \%$ while in 2011 , four hundred and three thousand and seventy $(403,070)$ candidates obtained a mean score of 47.33 equivalent to $25.19 \%$ and four hundred and twenty-seven thousand, three hundred and eighty-six $(427,386)$ candidates obtained a mean score of 55.88 equivalent to $31.17 \%$ in 2012 . Four hundred and thirty-seven thousand, eight hundred and forty-seven $(437,847)$ candidates sat for KCSE examinations and obtained a mean score of 49.66 equivalent to $27.79 \%$ in 2013. From the above observations, the percentage scores in 
Chemistry was low and lacked consistency over the years (KNEC, 2013).

In Narok County, performance in Chemistry in summative evaluation has been very poor and lack consistency.

Table 1: Chemistry KCSE Mean grades (MoE 2019)

\begin{tabular}{|c|c|c|c|c|c|c|}
\hline Year & 2012 & 2013 & 2014 & 2015 & 2016 & 2017 \\
\hline $\begin{array}{c}\text { Mean } \\
\text { Grade }\end{array}$ & 2.783 & 2.766 & 2.775 & 3.887 & 2.534 & 2.316 \\
\hline
\end{tabular}

From the mean grades above, performance has since been of low quality and lacking consistency. This inspired the study to find out issues behind such a continued trend.

\section{METHODOLOGY}

The research design selected was descriptive in which a sample group was used to provide information relating to the problem of study and the findings obtained were used to make generalizations. The area of study was Narok County. It is one of the 47 Counties in Kenya located in the Southern Rift Valley sharing borders with the Republic of Tanzania to the South, Nakuru County to the North, Bomet, Nyamira, Kisii and Migori Counties to the West, Kajiado County to the East. The target population comprised of 365 chemistry teachers and 6,314 students from a cohort of third years from secondary schools sponsored by the Kenyan government in Narok County. A sample of 377 subjects was obtained randomly from chemistry teachers and students. The findings were then generalized (Best and Khan 1993).

Research philosophy adopted was pragmatism which involved the use of quantitative and qualitative data to define relationships between the two variables Sauders, Lewis and Thornhill (2012). Data were collected through well-structured questionnaire, interview and observation schedule. The questionnaire included demographic characteristics such as gender, whether they do chemistry subject and statements regarding teaching resources in chemistry practical. Interview schedule consisted of questions relating to resources availability in chemistry practical. Observation schedule consisted of areas for observation during the actual practical activities. The instruments were given to the sampled group of students and interview guide given to the sampled chemistry teachers to be filled and both collected at the end of a given response time. The observation checklist was filled during the actual practical session where the students were observed as they handle practical activities. The County was selected because it long- delayed in the provision of excellent education to the learners attributed to inadequate infrastructure (NAYS, 2015).

Table 2: Population Targeted

\begin{tabular}{|c|c|}
\hline Respondents & Target population \\
\hline Chemistry teachers & 365 \\
\hline Students & 6,314 \\
\hline
\end{tabular}

Total Population

6679

Source: Ministry of Education (2019)

The sample size was determined by using Yamane's Taro formula, $\mathrm{n}=\mathrm{N} / 1+\mathrm{N}(\mathrm{e})^{2}$. Where $\mathrm{n}=$ Sample size, $\mathrm{N}=$ Population, $\mathrm{e}=$ acceptable sampling error of plus or minus $5 \%(0.05)$. Hence the results were given by;

$\mathrm{n}$

$$
=\frac{\mathrm{N}}{1+\mathrm{N}(e)^{2}}
$$

Where;

$\mathrm{n}=$ the sample size, $\mathrm{N}=$ the population size, $\mathrm{e}=$ the acceptance sampling error

$=6679 / 1+6679(.05)^{2}$

$=6679 / 1+16.6975$

$=6679 / 17.6975$

$=377$ respondents

Stratified sampling formula was used to calculate the proportion of respondents Neville \& Sidney (2013)

Sample size of the strata $=$ size of entire sample $/$ population size * layer size

$\mathrm{n}_{\mathrm{h}}=\left(\mathrm{N}_{\mathrm{h}} / \mathrm{N}\right) * \mathrm{n}$

Where;

$\mathrm{n}_{\mathrm{h}}$ is the sample size for stratum $\mathrm{h}, \mathrm{N}_{\mathrm{h}}$ is the population size for stratum $\mathrm{h}, \mathrm{N}$ is total population size, and $\mathrm{n}$ is total sample size as given below (Table 3 ).

Table 3: Sample Frame

\begin{tabular}{|c|c|c|}
\hline Respondents & Target population & $\begin{array}{c}\text { Sample } \\
\text { distribution }\end{array}$ \\
\hline Chemistry Subject & 365 & 21 \\
\hline Students & 6,314 & 356 \\
\hline Total & 6679 & 377 \\
\hline
\end{tabular}

Different sampling techniques were used i.e Cluster sampling technique, simple random sampling and purposive sampling all to achieve the required sample. Lottery was also used to avoid bias during selection. Research tools used were questionnaire, Interview and observation schedules. Data were analyzed using SPSS and Analysis of variance (ANOVA). Data were then presented using tables.

\section{RESULTS}

\section{Demographic Results}

Demographic results were summarized as given by the gender of the students as well as proportion of chemistry students. Genders of the students are presented in Table 4. 
Table 4: Gender of Students

\begin{tabular}{|c|c|c|c|c|c|}
\hline \multicolumn{2}{|c|}{} & $\begin{array}{c}\text { Freque } \\
\text { ncy }\end{array}$ & Percent & $\begin{array}{c}\text { Valid } \\
\text { Percent }\end{array}$ & $\begin{array}{c}\text { Cumulative } \\
\text { Percent }\end{array}$ \\
\hline \multirow{3}{*}{ Valid } & Male & 115 & 35.3 & 35.3 & 35.3 \\
\cline { 2 - 6 } & Female & 211 & 64.7 & 64.7 & 100.0 \\
\cline { 2 - 6 } & Total & 326 & 100.0 & 100.0 & \\
\hline
\end{tabular}

Source: Research Data (2019)

Based on gender out of 326 students who returned the research instrument 115 were male representing $35.3 \%$ while 211 were female representing $64.7 \%$. It means that there were more female than male in the schools within the region. This was a reflection from the Kenya population statistics showing more female than male persons from the 2019 census. Female students were given equal opportunities in school as male unlike in the past where most female students dropped out of school. $100 \%$ of students took chemistry subject in the third year cohort.

\section{Teaching Resources and Chemistry Performance}

The outcomes from questionnaire, interview and observation schedule were presented in this section.

\section{Questionnaire Results}

Teaching resources were evaluated against performance using the student questionnaire. Likert scale used was coded as $1=$ strongly disagree, $2=$ disagree, $3=$ neutral, $4=$ agree and $5=$ strongly agree, which was used to obtain frequencies and percentages of total frequency. These were used to obtain the mean that was used for interpretation as represented in Table 5 below.

Table 5: Teaching Resources and Chemistry Performance

\begin{tabular}{|c|c|c|c|c|c|c|}
\hline Questions & $5(\mathrm{SA})$ & 4(A) & $3(\mathrm{~N})$ & 2 (D) & $1(\mathrm{SD})$ & Mean \\
\hline $\begin{array}{c}\text { Chemistry apparatus are sufficient during practical } \\
\text { lessons. }\end{array}$ & $9(2.8 \%)$ & $34(10.4 \%)$ & $145(44.5 \%)$ & $109(33.4 \%)$ & $29(8.9 \%)$ & 2.65 \\
\hline $\begin{array}{c}\text { There is sufficient time allocation for chemistry practical } \\
\text { lessons }\end{array}$ & $32(9.8 \%)$ & $45(13.8 \%)$ & $171(52.5 \%)$ & $72(22.1 \%)$ & $6(1.8 \%)$ & 3.08 \\
\hline $\begin{array}{l}\text { Chemistry teachers provide sufficient reagents during } \\
\text { practical sessions }\end{array}$ & $17(5.2 \%)$ & $64(19.6 \%)$ & $118(36.2 \%)$ & $82(25.2 \%)$ & $45(13.8 \%)$ & 2.77 \\
\hline $\begin{array}{l}\text { There are sufficient chemistry teachers and lab } \\
\text { technicians for running chemistry practical }\end{array}$ & $62(19.0 \%)$ & $72(22.1 \%)$ & $65(19.9 \%)$ & $119(36.5 \%)$ & $8(2.5 \%)$ & 3.19 \\
\hline $\begin{array}{c}\text { The teacher assess the learners as they proceed with } \\
\text { chemistry practical }\end{array}$ & $30(9.2 \%)$ & $52(16.0 \%)$ & $114(35.0 \%)$ & $113(34.7 \%)$ & $17(5.2 \%)$ & 2.89 \\
\hline $\begin{array}{l}\text { Laboratory is well equipped with chemistry reagents and } \\
\text { apparatus for conducting practical. }\end{array}$ & $7(2.1 \%)$ & $21(6.4 \%)$ & $148(45.4 \%)$ & $108(33.1 \%)$ & $42(12.9 \%)$ & 2.52 \\
\hline
\end{tabular}

Source: Research Data (2019)

Table 5 presents students' responses on teaching resources and chemistry performance. The results indicated that chemistry apparatus were somehow not sufficient during practical lessons, where $9(2.8 \%)$ strongly agreed, $34(10.4 \%)$ agreed, 145(44.5\%) neutral, 109(33.4\%) disagreed and $29(8.9 \%)$ strongly disagreed. Therefore, chemistry apparatus were not enough during practical lessons (mean of 2.65). This mostly made students share or perform the practicals in shifts.

It was found that $32(9.8 \%)$ strongly agreed, $45(13.8 \%)$ agreed, 171(52.5\%) neutral, 72(22.1\%) disagreed and 6(1.8\%) strongly disagreed that there was sufficient time allocation for chemistry practical lessons (mean of 3.08). The results indicated that time allocation was somehow sufficient for chemistry practical lessons.

The response to whether chemistry teachers provided sufficient reagents during practical sessions indicated that $17(5.2 \%)$ strongly agreed, 64(19.6\%) agreed, 118(36.2\%) neutral, $82(25.2 \%)$ disagreed and $45(13.8 \%)$ strongly disagreed. A mean of 2.77 indicated that chemistry teachers did not provide sufficient reagents to be used in practical activities.

It was investigated if there were sufficient chemistry teachers and laboratory technicians' to administer practical. The response were 62(19.0\%) strongly agreed, 72(22.1\%) agreed, $65(19.9 \%)$ neutral, $119(36.5 \%)$ disagreed and $8(2.5 \%)$ strongly disagreed. Therefore, to small extent chemistry teachers and lab technicians were sufficient to facilitate chemistry practical (Mean of 3.19).

According to the results teachers assessed the learners as they proceeded with chemistry practical to some extent where $30(9.2 \%)$ strongly agreed, 52(16.0\%) agreed, 114(35.0\%) neutral, $113(34.7 \%)$ disagreed and 17(5.2\%) strongly disagreed. Hence it implied that teachers assessed the learners during practicals to a small extent (mean of 2.89).

Results also indicated that the laboratory contained apparatus and reagents necessary for conducting practical to small extent since $7(2.1 \%)$ strongly agreed, 21(6.4\%) agreed, $148(45.4 \%)$ neutral, $108(33.1 \%)$ disagreed and $42(12.9 \%)$ strongly disagreed. It implied that most laboratories had apparatus and reagents for conducting practical (mean of 2.52) but were not adequate to accommodate individual student activities.

\section{Interview Results}

Interview schedule was utilized to interrogate chemistry teachers on the effect of teaching resources on performance in chemistry. This followed an interview question inquired if practical apparatus were available for chemistry practicals. Teachers accepted that apparatus and reagents were available but not sufficient. The main issue stated by the chemistry 
teachers was the adequacy of the apparatus since majority of the schools did not have sufficient apparatus that led them to put their students in groups and also performed the experiments in shifts. Chemistry teacher 12 commented that "the main challenge in apparatus is not the availability but the adequacy. The apparatus is sufficient to cover a class of 50 students and often we create shifts to enable individual participation. Most of the time three groups are formed which has led to lack of sufficient time to conduct the individual practicals. This forced majority of chemistry teachers to conduct group experiments where each experiment was conducted by three to five students depending on the available apparatus". This argument of chemistry teacher 12 was shared by majority of chemistry teachers. Some associated poor performance of chemistry to inadequacy of laboratory resources. Chemistry teacher 21 alluded that, "The poor results that we have are contributed by other factors but the major challenge in our school is lack of sufficient apparatus which has crippled chemistry teachers' effort to reverse the trend of poor performance. The day secondary schools should be allocated more funds to purchase apparatus, reagents and build laboratories for better chemistry performance."

The second interview question on teaching resources was on time allocation for practicals. Chemistry teachers argued that if the laboratory had sufficient space, apparatus and reagents the time allocated in the timetable was sufficient and they could not find extra time during weekends, morning and evening for practicals. According to teacher 6 argument, "the time is not the problem here but the available resources which is always the issue". "In some practicals to test individual competence, we divide the class into three to four shifts so that individual students perform the experiments". This forced the chemistry teachers to organize for individual practical sessions during the weekends to have adequate space and apparatus for the experiments. "But often we are forced to conduct experiments in groups which fit the time allocated in the timetable". This was replicated in other responses where time allocation depended on whether its group or individual based practical which dependent on the space and physical resources availability.

Interview of whether there were sufficient reagents for chemistry practicals revealed that the sufficiency differed with different schools. According to the results it was found that schools that had resources mostly the National and extraCounty schools did not have an issue with sufficiency of reagents. The problem mainly affected the County and day secondary schools. This reason made students conduct practicals in groups and some time the teachers carried out demonstration. Chemistry teacher 1 reiterated that, "the school needs to provide sufficient reagents for practicals despite the challenge of insufficient apparatus because the students could be organized to share. There was also a challenge of insufficient reagents which most of the time led to setting groups of 4 to 5 students per experiment. The government through the school management should increase the budget allocated to apparatus and reagents in secondary schools to enhance scientific instructional practices.

Interview of whether chemistry teachers and lab technicians were sufficient. Chemistry teacher 17 provided a profound comment that "Teachers are not the problem they are sufficient based on workload and sometimes the school did employ when necessary but the main challenge is a large class which is difficult to manage during practical sessions". This required more resources based on the space in the laboratory, apparatus and reagents which most of the time are not sufficient. These sentiments were shared by majority of the chemistry teachers that there was need to consider physical resources and the school should allocate more teachers through contract based employment.

\section{Observation Results}

Observations on teaching resources were analyzed using mean and standard deviation. The data obtained is shown in Table 6 below;

Table 6: Observation on teaching resources

\begin{tabular}{|c|c|c|c|}
\hline & $\mathrm{N}$ & Mean & $\begin{array}{c}\text { Std. } \\
\text { Deviatio } \\
\mathrm{n}\end{array}$ \\
\hline $\begin{array}{c}\text { There are enough apparatus in the } \\
\text { laboratory }\end{array}$ & 21 & 3.2857 & .56061 \\
\hline $\begin{array}{c}\text { Chemical reagents are adequate } \\
\text { for all the students }\end{array}$ & 21 & 2.7143 & .78376 \\
\hline $\begin{array}{c}\text { The laboratory is adequate for the } \\
\text { chemistry practicals }\end{array}$ & 21 & 1.8095 & .67964 \\
\hline
\end{tabular}

Source: Research Data (2019)

Findings indicated that apparatus were available but not adequate (mean of 3.2857). Variation was low (standard deviation of .56061). Chemistry reagents were somewhat not adequate for all the students (mean of 2.7143). Dispersion was low (standard deviation of .78376). Chemistry laboratory space was not adequate for the chemistry practical session (mean 1.8095). Variation was low in (standard deviation of .67964).

\section{ANOVA results}

Teaching resource was tested against chemistry performance using ANOVA analysis. The following results were achieved.

Table 7: ANOVA Teaching Resource and Chemistry Performance

\begin{tabular}{|c|c|c|c|c|c|c|c|}
\hline \multicolumn{2}{|c|}{} & $\begin{array}{c}\text { Sum } \\
\text { of } \\
\text { Squar } \\
\text { es }\end{array}$ & df & $\begin{array}{c}\text { Mean } \\
\text { Squar } \\
\text { e }\end{array}$ & F & $\begin{array}{c}\text { Sig } \\
\cdot\end{array}$ \\
\hline $\begin{array}{c}\text { Performance } \\
\text { in chemistry } \\
\text { practical } * \\
\begin{array}{c}\text { Resource in } \\
\text { chemistry } \\
\text { laboratory }\end{array}\end{array}$ & $\begin{array}{c}\text { Betwe } \\
\text { en } \\
\text { Group }\end{array}$ & $\begin{array}{c}\text { S } \\
\text { (Comb } \\
\text { ined) }\end{array}$ & 22.726 & 4 & 5.682 & $\begin{array}{c}8.6 \\
17\end{array}$ & $\begin{array}{c}.00 \\
0\end{array}$ \\
\cline { 2 - 8 } & \multicolumn{2}{|c|}{ Total Groups } & $\begin{array}{c}211.65 \\
7\end{array}$ & $\begin{array}{c}32 \\
1\end{array}$ & .659 & & \\
\hline
\end{tabular}

Source: Research Data (2019) 
Table 7 reveals that teaching resources has significant effect on performance in chemistry $\left(\mathrm{F}_{(\mathrm{P}=5 \%, 4,321)}=8.617, \mathrm{P}=0.000\right.$ $<0.05$ ). F- ratio between group variance to within group is 8.617, the value is closer to the mean hence variance is low. $\mathrm{P}<0.05 \%$ the value is less than $5 \%$ which means that there is a significant relationship between variables and hence null hypothesis is rejected and alternative hypothesis accepted. Laboratory apparatus and reagents are crucial in chemistry practical and had an impact on chemistry performance.

\section{DISCUSSION OF TEACHING RESOURCES AND CHEMISTRY PERFORMANCE RESULTS}

The results indicated that chemistry apparatus were not enough during practical lessons mean of 2.65. The main issue was inadequacy. This made teachers to administer practical in groups or in shifts. Time allocation was somehow sufficient for the chemistry practicals mean of 3.08 but could not suit individual students to handle practicals at the same time. Chemistry teachers could not provide sufficient reagents during practical with an aggregate mean of 2.77 . The inadequacy of apparatus and reagents coupled with shortage of time for individualized exposure to practical activities could have contributed to poor results during summative evaluation in this study.

It was also found that chemistry teachers and laboratory technicians were somewhat sufficient to manage chemistry practicals with mean of 3.19. The main challenge was difficulty when handling large classes which stressed the available resources. The teachers were unable to carry out assessment during practical sessions mean of 2.89. Majority of the laboratories were not equipped with apparatus and reagents for conducting practical (mean of 2.52).

ANOVA results indicated that teaching resources contributed significantly to the performance in chemistry subject $(\mathrm{P}<0.05)$. The results showed that reagents and apparatus were available but not sufficient for all the students based on inadequate space in laboratories as reported by chemistry teachers. This led teachers resort to demonstration and practical activities done in groups or shifts. The space was the main concern that made majority of teachers to use groups when conducting experiments. This inadequacy may have contributed to students performing below average in national exams. This was similar to the observation made as students handled practicals.

The finding of the study revealed that teaching resources contributed significantly to the performance in chemistry subject. When the students are exposed to practical activities more often, they acquire sufficient skills and broaden their understanding of chemistry content hence enabling them perform better in summative evaluation. This is supported by Adalikwu and Iorkpilgh (2013) who noted that instructional materials (teaching aids) significantly affected performance of chemistry. The study was based on an experiment where the experimental group with sufficient instructional material performed better than those without instructional materials.
The finding of the study revealed although practical time was allocated in the school master timetable it could not accommodate individual students handle practices. This was due to inadequate laboratory space in relation to large class sizes. This was criticized by Chen and Wei (2015) who reported that the adaptation of curriculum material was affected by time constraints, external examinations and teacher's pedagogical content knowledge. But the use instructional materials in teaching enhances understanding of concepts in chemistry therefore, there is need to balance the instructional methods employed against time availability and relevance to national examinations.

The finding of the current study showed that laboratory apparatus and reagents were not sufficient for practical activities. The inadequacies made the students not to do individualized experiments affecting their scientific skills development necessary for evaluation. The finding led credence to the findings of Gutierrez (2014) who found that limitation of laboratory equipment, laboratory room management and learning environment are the main challenges that affected experimental based learning. Since chemistry is a research oriented subject there is need for provision of sufficient experimental requirements to enhance teaching and learning. Instructional materials generally enabled the students understand concepts in Chemistry and therefore leading to high academic achievement.

\section{CONCLUSIONS}

Majority of laboratories were not well equipped with apparatus and reagents for conducting practicals and inadequate to accommodate large classes. Apparatus and reagents were provided for students to work in groups and occasionally in shifts. Time allocation for practical and theory was as per the time table although was inadequate for individualized activities. Chemistry laboratory space was not adequate for practical activities. Teaching resources had significant influence on performance in chemistry practical and the entire subject.

\section{RECOMMENDATIONS}

- School management and teachers should provide sufficient apparatus and reagents for practical administration.

- The government should invest more in infrastructural development especially of science laboratories to meet the demands of increased number of students caused by the government policy of $100 \%$ transition

\section{REFERENCES}

[1] Achimugu, L. (2012). Strategies for Effective Conduct of Practical Chemistry Works in Senior Secondary Schools in Nigeria. Retrieved 22 August, 2014, 1:32 pm, Adobe Acrobat Document.

[2] Adalikwu, S. and Iorkpilgh, I. (2013). The influence of instructional material on academic performance of senior secondary school students in Chemistry in Cross River State. Global Journal of Educational Research Vol 12, 2013: pp 39-45

[3] Best, J. W. and Khan, J. V. (1993) Research Methodology. $5^{\text {th }}$ Edition, New Delhi, India. 
[4] Chen, B. and Wei, B. (2015). Investigating the Factors that Influence Chemistry Teachers' Use of Curriculum Materials: The Case of China. Science Education International, 26(2), 195-216.

[5] Edomwonyi-Otu, L. (2011). The Challenge of Effective Teaching of Chemistry. Bello University: Zaria.

[6] Gutierrez, R. (2014). Determinants of Chemistry Performance of Teacher Education Students of State Colleges and Universities in Cagayan Valley. International Conference on Economics, Education and Humanities. No. 14. Indonesia.

[7] Kenya National Examination Council, (2009). Kenya Certificate of Secondary Examination Annual report. Nairobi.

[8] Kenya National Examination Council, (2013). Kenya Certificate of Secondary Examination Annual Report. Nairobi.
[9] Ministry of Education, (2019). Kenya Certificate of Secondary Education Chemistry results Analysis. Narok.

[10] NAYS, (2015). Kenya National Adolescents and Youth Survey, Nairobi, Kenya: NCPD

[11] Neville, H. and Sidney, T. (2013). Stratified Sampling. Webpage at Coventry University. Retrieved on 3th March 2020.

[12] Odum, J. (2013). Assessment of Secondary School Chemistry Teachers' Quality Through Identification and use of Laboratory Apparatus' Journal of Education and Practice, ISSN 2222-1735 vol. 4, No 5,

[13] Saunders,M., Lewis, P and Thornhill, A. (2012) "Research Methods for Business Students" $6^{\text {th }}$ edition, Pearson Edition Limited. 